\title{
Heroin Induced Hypersensitivity Pneumonitis
}

\author{
Michael Bond ${ }^{1}$, Kenneth Butler ${ }^{1}$, Adam Richardson ${ }^{2}$, and Kelly Blosser ${ }^{3}$ \\ ${ }^{1}$ University of Maryland School of Medicine \\ ${ }^{2}$ University of Maryland Medical System \\ ${ }^{3}$ University of Maryland Medical Center
}

February 19, 2021

\begin{abstract}
A 49-year-old woman presented to the emergency department with dyspnea, a respiratory rate of 26 times per minute and a room air oxygen saturation of $69 \%$ after nasal inhalation of heroin. A chest computed tomography angiogram (CTA) revealed diffuse ground-glass opacities in all five lung lobes representing hypersensitivity pneumonitis
\end{abstract}

\section{Hosted file}

Manuscript Heroin Induced Hypersensitivity Pneumonitis.pdf available at https://authorea.com/ users/396661/articles/509789-heroin-induced-hypersensitivity-pneumonitis 


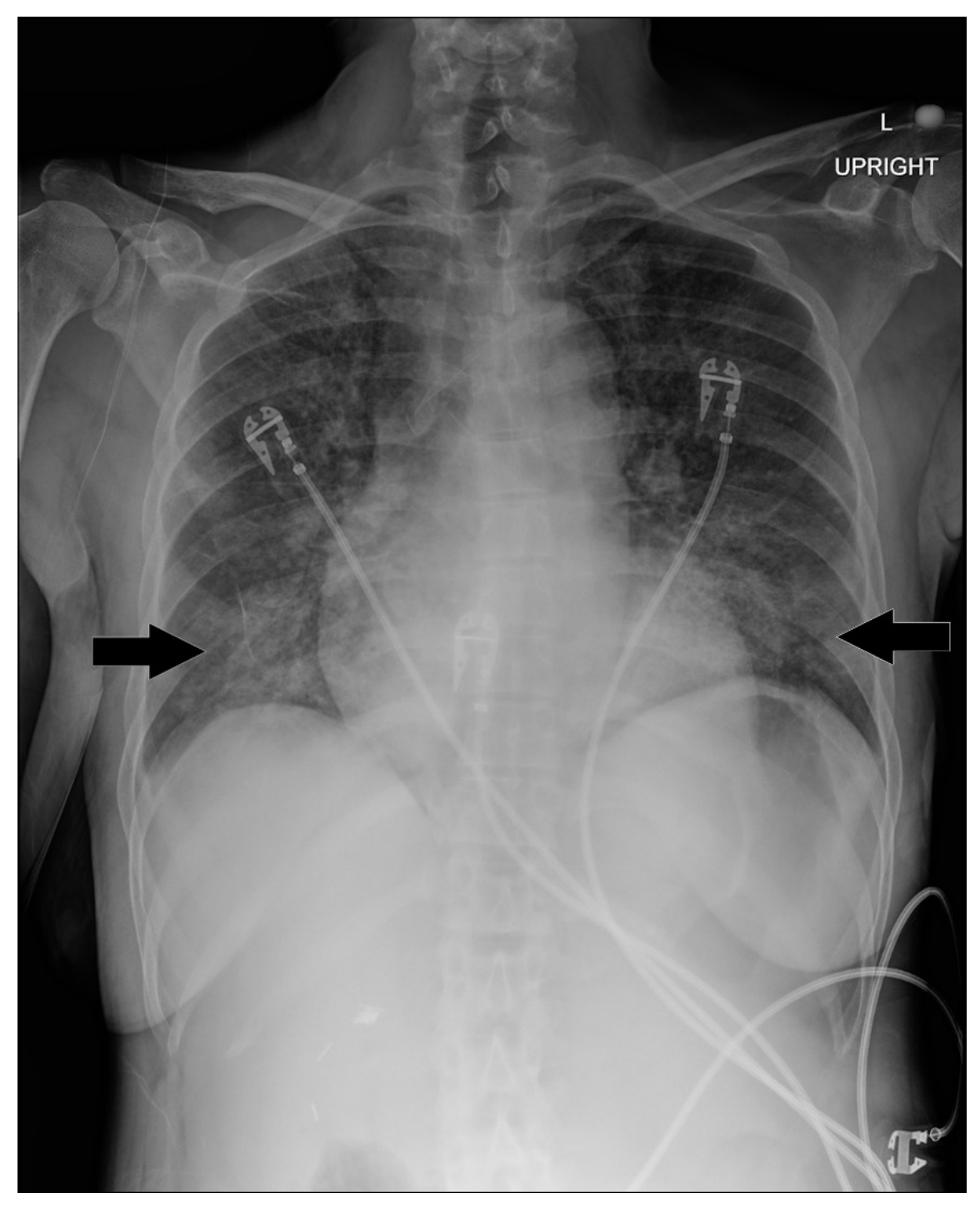




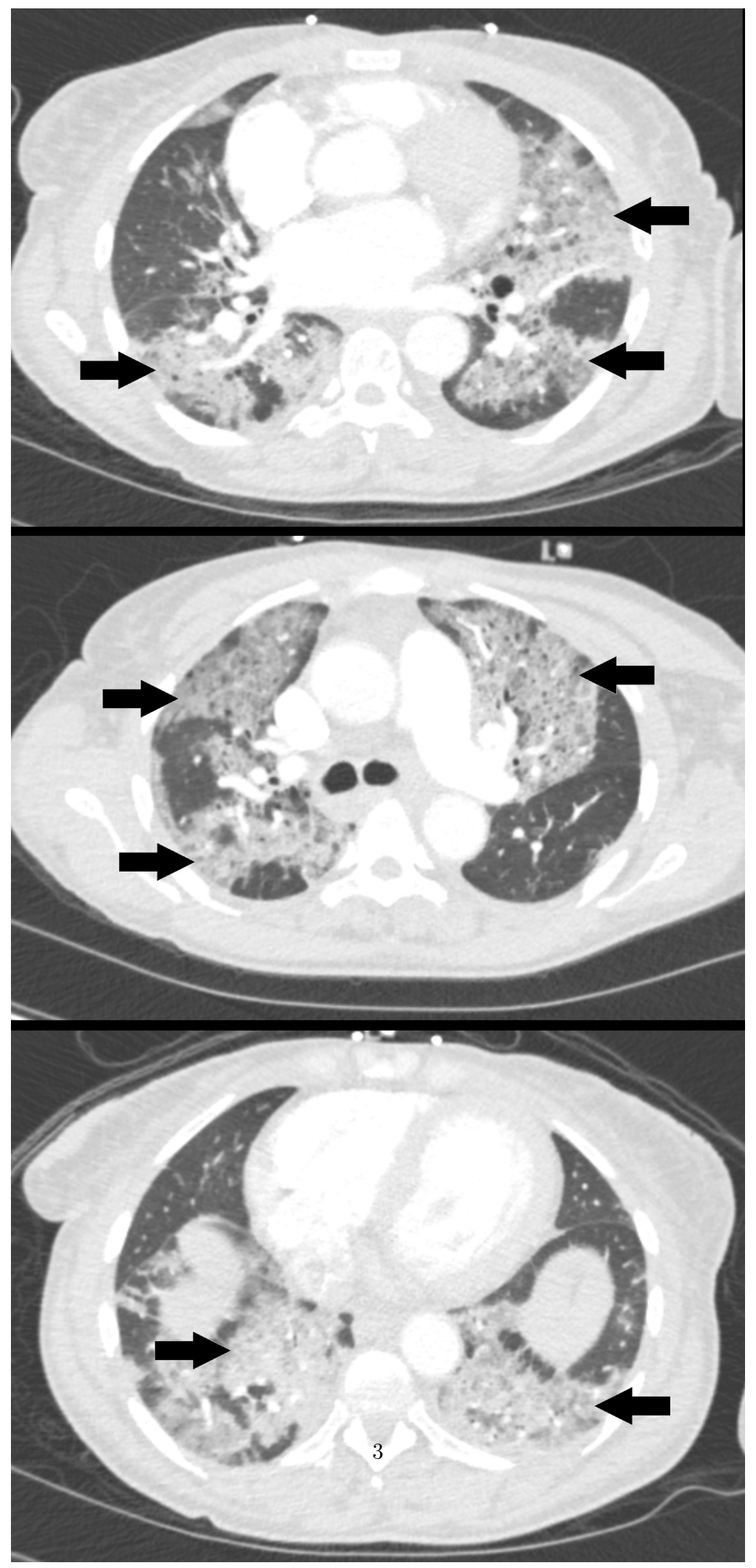

